http://jmscr.igmpublication.org/home/ ISSN (e)-2347-176x ISSN (p) 2455-0450

crossref DOI: https://dx.doi.org/10.18535/jmscr/v9i2.23

\title{
The Effect of Topical Nano Silver Gel on Diabetic Foot Ulcer - A Randomised Control Study in Tertiary Care Centre
}

\author{
Authors \\ Ajay.P (MS General Surgery) ${ }^{1}$, Dinker Pai ${ }^{2}$ \\ ${ }^{1}$ Senior Resident, Mahatma Gandhi Medical College, Pondicherry \\ ${ }^{2}$ Professor, Mahatma Gandhi Medical College, Pondicherry
}

\begin{abstract}
Aim: To study the efficacy of Nano crystalline silver in the management of diabetic foot ulcers

Methods: patients with diabetic foot ulcer were divided into two Groups using randomized number generator. Group 1 was test group for Nano silver gel dressing \& group 2 was control group for conventional dressing. The effect of each dressing was compared for reduction in wound size, time to full granulation and number of hospital days.

Results: In our study there was no statistical significant different in the size of ulcer in the pre-treatment phase across case and control group. Final size of ulcer after the treatment was found to be statistically significant across case and control group $(9.56 \pm 2.8 \mathrm{~cm}$ VS 13.24 \pm 3.85$), P$ value was $<0.001$. The mean granulation day in the test group was $17.22 \pm 4.27$ days, while among the control group $22.02 \pm 3.98$ days, this difference in the mean was found to be significant ( $p<0.001)$. Difference in the duration of hospital stay across test and control group was $24.46 \pm 4.89$ days, $33.56 \pm 4.59$ days respectively. This difference was found to be significant $(p<0.001)$. Thus in the test group mean size of ulcer after the dressing was smaller in test group than control group, mean granulation days and mean duration of stay was lesser in the test group.

Conclusion: In this study, there was significant reduction in wound size, the time for full healthy granulation appearance and the duration of hospital stay was better compared to the conventional dressing.

Keywords: Diabetic foot, Diabetic foot ulcer, nano silver gel.
\end{abstract}

\section{Introduction}

Diabetic foot ulcers are very common among Indian population with anprevalence rate of $2.4 \%$ in rural and $12-17 \%$ in urban Indian population. Diabetic foot ulcer is a major complication of diabetes mellitus. Approximately 15 percent of patients with diabetes develop ulcers. ${ }^{1}$ Foot ulceration and infection are the major causes of hospitalization in people with diabetes. Dressings have a major part to play in the management of wounds by providing a moist wound environment and promote healing. Key feature of wound healing are repair of lost extracellular matrix (ECM) that forms the largest component of the dermis. Diabetes Mellitus being a metabolic disorder has a prolonged inflammatory phase which causes a delay in the formation of mature granulation tissue and a parallel reduction in wound tensile. ${ }^{2}$ 
Silver has been used as an antimicrobial since the 1800s. But since the discovery of systemic antibiotics in the early 20th century, the use of silver has declined. In the last two decades interest in silver for wound treatment resurged. ${ }^{3}$

Silver has antiseptic, antimicrobial, antiinflammatory properties and is a broad spectrum antibiotic. ${ }^{6}$ Silver is known to be a germicide (silver nitrate and silver sulphadiazine) for a long time. Silver destroys microorganisms immediately by blocking the cellular respiration and disrupting the function of bacterial cell membranes. Silver ions also bind and denature the bacterial DNA and RNA, thus inhibiting cell replication. ${ }^{7}$

The improvement of nanochemistry has created miniaturized scale fine particles which increment silver's dissolvability and discharges silver particles in concentration of 70-100 ppm. Nanocrystalline silver framework destroys all microorganisms found in the injury including organisms, MRSA and vancomycin-safe enterococcus (VRE). ${ }^{5}$

Nano crystalline silver utilizes nanotechnology to release clusters of extremely small and highly reactive silver particles. The smaller the particles of silver, the greater the wound surface area that will be in contact with silver, thus increasing bioactivity and silver solubility. ${ }^{8}$

The purpose of this study is to demonstrate the effectiveness of Nano silver dressing over conventional dressing in diabetic foot ulcers.

\section{Subjects and Methods}

This was a prospective randomized study, which was conducted at our Institute, a tertiary care hospital.

The Institutional Human Ethics Committee approved this study, from November 2016 to April 2018. Written informed consent was obtained from the patients.

\section{Study Population}

Patients attending the Department of General Surgery, who fulfilled the inclusion criteria admitted in General Surgery ward in Institute were considered for randomization into patients receiving nano silver gel dressing and the ones who received conventional normal saline dressing.

\section{Inclusion Criteria}

- Patients aged more than 18 years

- All diabetic wounds - Grade I,II,III. (Wagner's Classification)

\section{Exclusion Criteria}

- Other clinically significant medical conditions that would impair wound healing like renal, hepatic, hematological, neurological, and immunological diseases.

- Patients receiving corticosteroids, immunosuppressive agents, radiation, or chemotherapy within one month prior to entry into the study were also excluded.

\section{Sampling Procedure}

- Patients who fell under the selection criteria and who voluntarily agreed to be involved in the study were enrolled.

- An informed consent was obtained from each patient recruited for this study after explaining the nature of study and the possible investigations involved in the study.

\section{Study Groups}

Group 1 - Experimental Nano silver gel dressing - 50 patients.

Group 2 - Conventional dressing -50 patients.

\section{Sample Size}

Group 1 - Experimental Nano silver gel dressing 50 patients.

Group 2 - Conventional dressing -50 patients.

\section{Result}

Most of diabetic foot patients were in the age group of 50-59 years and 40-49 years $(26 \%, 25 \%)$ (Figure 1) and mean age presentation to our hospital was 46 years. The youngest was 27 who came with ulcer over sole and eldest was 88 year who came with ulcer over foot and toes. 


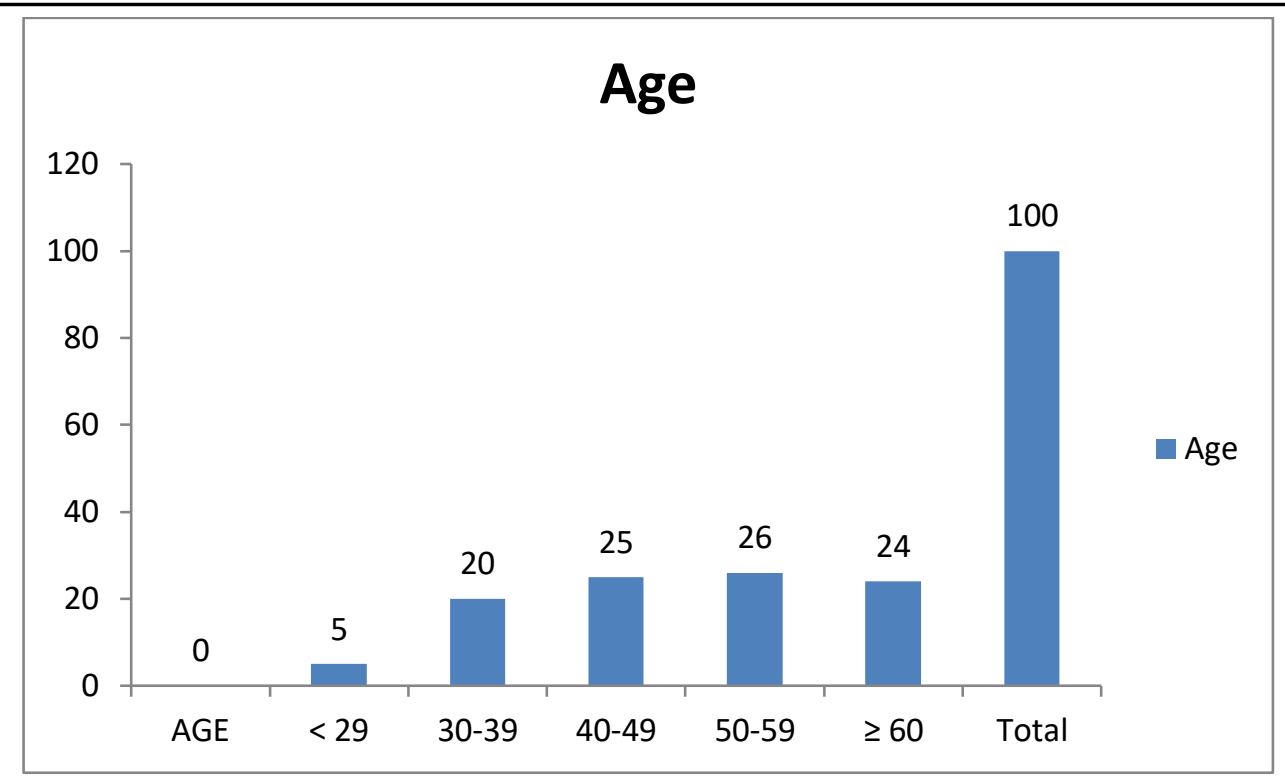

Figure 1: Age distribution

In the test group $72 \%$ were males and $28 \%$ were females, compared to $22 \%$ women and $78 \%$ men in the control group. There was no statistical difference for age between the 2 groups $(\mathrm{p}=0.48)$ as shown in table 1.

Table 1: Comparison of mean age between test and control group

\begin{tabular}{|c|c|c|c|}
\hline Age & Male & Female & P value \\
\hline Test & 36 & 14 & \multirow{2}{*}{$=0.48$} \\
\hline Control & 39 & 11 & \\
\hline
\end{tabular}

Out of 100 cases studied there was male predominance in occurrence of diabetic foot ulcers. $75 \%$ were male and $25 \%$ were female patients. Gender distribution was equal in both test and control group ( $\mathrm{p}$ valve $=0.48$ ) figure 2

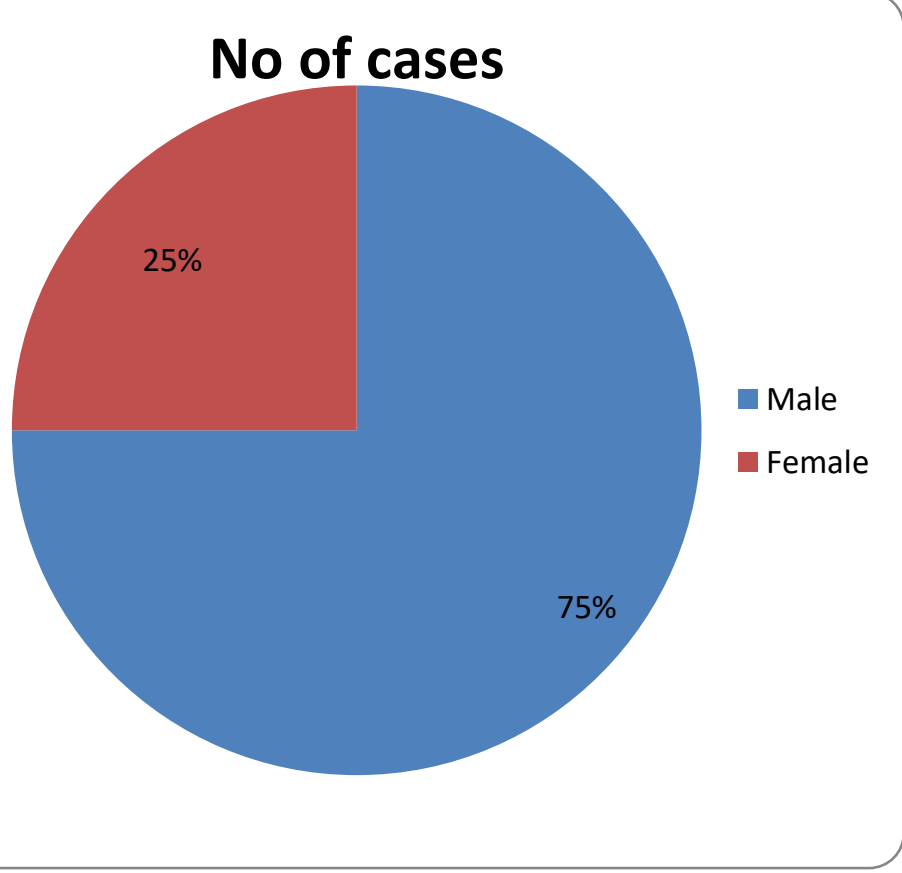

Figure 2: Gender distribution 
The most common presentation of diabetic foot ulcers was in toes $(31 \%)$, dorsum of foot $(28 \%)$,
Plantar aspect of foot $(27 \%)$ and Ankle joint $(14 \%)$ as shown in figure 3

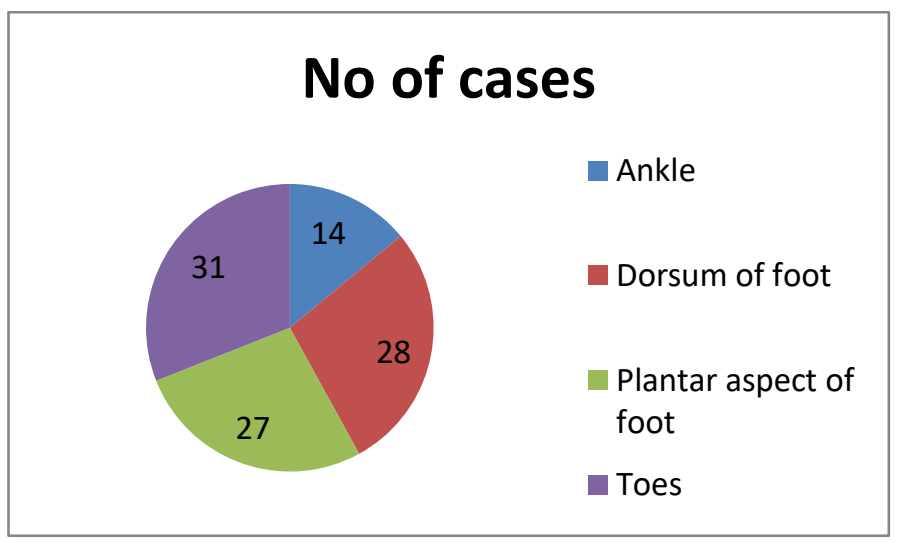

Figure 3: Site of the lesion

Among the test group, which received nano- silver ointment dressing, it was seen that only $24 \%$ of the ulcer was in grade 1 and $76 \%$ in grade 2.
Table 2 shows that in the control group, $26 \%$ had ulcer of grade 1 and $74 \%$ had ulcer of grade 2 .

Table 2: Grades of ulcer among test group and control group

\begin{tabular}{|c|c|c|c|}
\hline Grade of ulcer & $\begin{array}{c}\text { No of cases in test } \\
\text { group \% }\end{array}$ & $\begin{array}{c}\text { No of cases in control } \\
\text { group \% }\end{array}$ & P value \\
\hline Grade I & $12(24 \%)$ & $13(26 \%)$ & \multirow{2}{*}{$=0.81$} \\
\hline Grade II & $38(76 \%)$ & $37(74 \%)$ & \\
\hline
\end{tabular}

There was no significant difference in grade of ulcers between the two groups ( $\mathrm{p}$ value $=0.81$ ).

Table 3 shows that, there was no statistical significant different in the size of ulcer in the pretreatment phase across case and control group. Final size of ulcer after the treatment was found to be statistically significant across case and control group (9.56 $\pm 2.8 \mathrm{~cm}$ VS $13.24 \pm 3.85)$, P value was $<0.001$. The mean for healthy granulation day in the test group was $17.22 \pm 4.27$ days, while among the control group $22.02 \pm 3.98$ days, this difference in the mean was found to be significant $(\mathrm{p}<0.001)$. Difference in the duration of hospital stay across test and control group was $24.46 \pm 4.89$ days, $33.56 \pm 4.59$ days respectively. This difference was found to be significant $(\mathrm{p}<0.001)$.

Table 3: Comparison of various parameters among case and control group

\begin{tabular}{|c|c|c|c|c|}
\hline Parameters & GROUP & $\mathbf{N}$ & Mean & $P$ value \\
\hline \multirow{2}{*}{$\begin{array}{l}\text { Pre treatment size } \\
\text { of ulcer }\end{array}$} & Case & 50 & $16.082 \pm 4.7791$ & \multirow[t]{2}{*}{0.13} \\
\hline & Control & 50 & $14.776 \pm 3.8069$ & \\
\hline \multirow[t]{2}{*}{ Final size of ulcer } & Case & 50 & $9.560 \pm 2.8443$ & \multirow[t]{2}{*}{$<0.001$} \\
\hline & Control & 50 & $13.248 \pm 3.8554$ & \\
\hline \multirow{2}{*}{$\begin{array}{l}\text { Time for full } \\
\text { Granulation }\end{array}$} & Case & 50 & $17.22 \pm 4.278$ & \multirow[t]{2}{*}{$<0.001$} \\
\hline & Control & 50 & $22.02 \pm 3.987$ & \\
\hline \multirow{2}{*}{$\begin{array}{l}\text { Duration of } \\
\text { hospital stay }\end{array}$} & Case & 50 & $24.46 \pm 4.892$ & \multirow[t]{2}{*}{$<0.001$} \\
\hline & Control & 50 & $33.56 \pm 4.590$ & \\
\hline
\end{tabular}




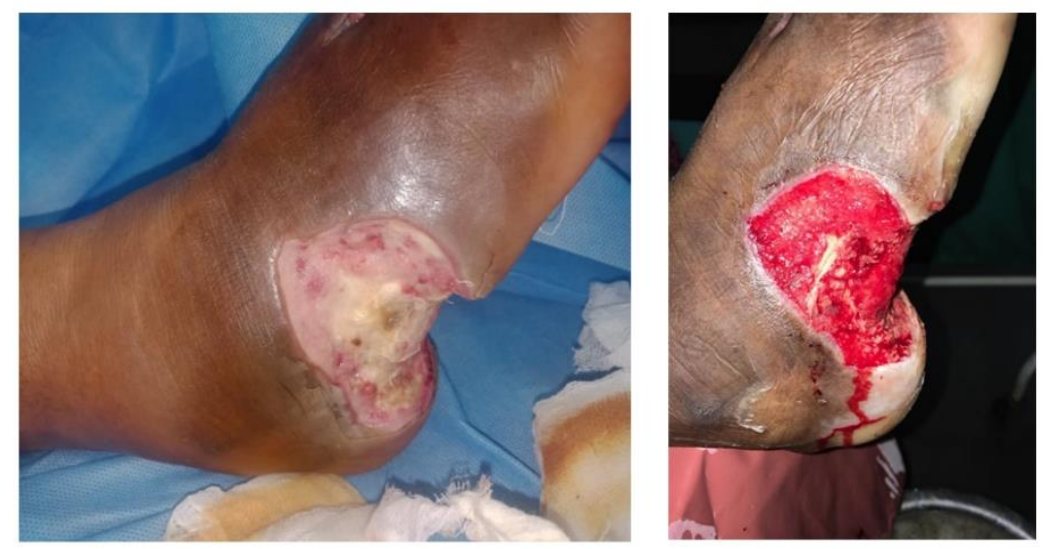

Figure 4: Comparison of initial and final granulation tissue

\section{Discussion}

This study was conducted to study the effect of topical nano silver gel on diabetic foot ulcer. There were total 100 participants in the study, 75 males and 25 females. Participants were divided into two groups; test group had 36 males and 14 females, while control group contained 39 male and 11 females. There was no statistical difference for gender among groups. Our study showed a greater male preponderance $75 \%$ compared to the other studies $58 \%$ for Tsang KK et al. ${ }^{9}$ In the study conducted by Qari FA etal ${ }^{10}$ majority of patients were male above 50 years, mean age $59 \pm 9.6$, as compared to our study population which had a mean age of $46 \pm 4.5$ years (range from 27 to 88 years).

In this study various site of lesion for ulcer presentation was ankle, dorsum of foot, plantar aspect of foot and toes. It was found that the most common presentation of diabetic foot ulcers was in toes (31\%) followed by dorsum of foot $(28 \%)$, plantar aspect of foot (27\%) and ankle joint (14\%).Findings of the present study was comparable to Khan AA etal where the most common site of lesion was also toes which was around $38 \%$ followed by dorsum of foot involved in 18 patients $(30 \%)$. Similar results were also seen in the study done by Apelquist et al and Reiber et al. In their study the second most common site of involvement was plantar (metatarsal heads, mid foot and heel) whereas in the present study it was the dorsum of foot.In the study done by Qari FA etal ${ }^{10} 38 \%$ had ulcer of foot and $35 \%$ had ulcer on the toe. In a study conducted by Edmond et al, in 1986, it was seen that $93 \%$ of foot ulcers were on plantar and forefoot area.

Among the test group which received an non silver ailment dressing it was seen that $24 \%$ of ulcers were grade I and 76 in grade II, while in the control group 26 had ulcer of grade I and 74\% had ulcer of grade II. Sharma R etal ${ }^{11}$, on the other hand, had the two grades evenly distributed (50 vs $50 \%)$ in the silver colloid group and in the conventional group (54 vs 46\%)

Both test and control groups had similar pretreament ulcer size $(\mathrm{p}=0.13)$, but it was seen that the final size of ulcer after the treatment was significantly smaller in the test group $(9.56 \pm 2.8$ $\mathrm{cm}$ VS $13.24 \pm 3.85 \mathrm{P}$ value was <0.001). The mean time for full granulation in the test group was $17.22 \pm 4.27$ days, while among the control group $22.02 \pm 3.98$ days, this difference in the mean was found to be significant $(\mathrm{p}<0.001)$. This meant that patients with nano silver dressing healed faster. This was also reflected in the shorter hospital stay in this group (24.46 \pm 4.89 days, $33.56 \pm 4.59$ days $\mathrm{p}=<0.001$ ) respectively.

Gottrup et al. ${ }^{13}$ studied the use of collagen silver against standard care in diabetic foot ulcer. It was seen that there were significantly more responders in the collagen silver group while as compared to control group. Kwakman et al. ${ }^{14}$ compared the effect of medicinal honey and nano silver on the healing of ulcer, it was seen that the antibacterial effect of nano silver was better than medicinal 
honey in epithelisation. Miller et al. ${ }^{15}$, Sharma R etal $^{16}$ also found that nano silver reduced wound size more when compared to the control group. In contrast, Fries et al. ${ }^{12}$ found that the days of wound healing in the nano silver group were slightly longer than those of the control group but the result had no significant difference.

\section{Limitations of the Study}

The study was limited by the small sample size especially for each grade of ulcer.

\section{Conclusion}

In this study, there was significant reduction in wound size, the time for full healthy granulation appearance and the duration of hospital stay was better compared to the conventional dressing.

\section{Reference}

1. Winter GD. Formation of scab and rate of epithelialization of superficial wounds in the skin of the young domestic pig. Nature 1962;193:293-4.

2. Cho CY, Lo JS. Excision and repair: Dressing the part. Dermatol Clin 1998; 16:25-47.

3. Moon $\mathrm{CH}$, Crabtree TG. New wound dressing techniques to accelerate healing. Curr Treat Options Infect Dis 2003;5: 25160.

4. Varghese MC, Balin AK, Carter DM, Caldwell D. Local environment of chronic wounds under synthetic dressings. Arch Dermatol 1986; 122: 52-7.

5. Alvarez OM, Mertz PM, Eaglstein WH. The effect of occlusive dressings on collagen synthesis and reepithelialization in superficial wounds. J Surg Res 1983; 35:142-8.

6. Rubio PA. Use of semiocclusive, transparent film dressings for surgical wound protection: An experience in 3637 cases. IntSurg1991;76:253-4.

7. Lineaweaver W, Howard R, Soucy D, Mc Morris S, Freeman J, Crain C et al. Topical antimicrobial toxicity. Arch Surg 1985;120:267-70.

8. White RJ, Cutting K, Kingsley A. Topical antimicrobials in the control of wound bioburden. Ostomy Wound Manage 2006;52:26-58.

9. Tsang KK, Kwong EW, To TS, Chung JW, Wong TK. A pilot randomized, controlled study of nanocrystalline silver, manuka honey, and conventional dressing in healing diabetic foot ulcer. EvidenceBased Complementary and Alternative Medicine. 2017;2017

10. Qari FA, Akbar D. Diabetic foot: presentation and treatment. Saudi medical journal. 2000;21(5):443-6.

11. Sharma R, Gupta N, Kumar V, Pal S, Kaundal V, Sharma V. Silver colloid dressings score over conventional dressings in diabetic foot ulcer: a randomized clinical trial. International Surgery Journal. 2017 Jul 24;4(8):262731.

12. C. A. Fries, Y. Ayalew, J. G. PennBarwell, K. Porter, S. L. A. Jeffery, and M. J. Midwinter, "Prospective randomised controlled trial of nanocrystalline silver dressing versus plain gauze as the initial post-debridement management of military wounds on wound microbiology and healing," Injury, vol. 45, no. 7, pp. 11111116, 2014..

13. F. Gottrup, B. M. Cullen, T. Karlsmark, M. Bischoff-Mikkelsen, L. Nisbet, and M. C. Gibson, "Randomized controlled trial on collagen/oxidized regenerated cellulose/silver treatment," Wound Repair and Regeneration, vol. 21, no. 2, pp. 216225, 2013

14. P. H. S. Kwakman, A. A. te Velde, L. de Boer, C. M. J. E. Vandenbroucke-Grauls, and S. A. J. Zaat, "Two major medicinal honeys have different mechanisms of bactericidal activity," PLoS ONE, vol. 6, no. 3, Article ID e17709, 2011 
15. C. N. Miller, N. Newall, S. E. Kapp et al., "A randomized-controlled trial comparing cadexomer iodine and nanocrystalline silver on the healing of leg ulcers," Wound Repair \& Regeneration, vol. 18, no. 4, pp. 359-367, 2010.

16. Sharma R, Kumar R, Mittal S, Kaur A. Study of effect of topical nano silver gel on wound healing. Journal of Advanced Medical and Dental Sciences Research. 2016 Sep 1;4(5):59. 